\title{
Estrogenic and mutagenic activities of Crotalaria pallida measured by recombinant yeast assay and Ames test
}

\author{
Paula Karina Boldrin ${ }^{1}$, Flávia Aparecida Resende ${ }^{1 *}$, Ana Paula Oliveira Höhne1, Mariana Santoro de Camargo ${ }^{\text {, }}$ \\ Lívia Greghi Espanha', Catarine Haidê Nogueira', Maria do Socorro F Melo², Wagner Vilegas² \\ and Eliana Aparecida Varanda ${ }^{1}$
}

\begin{abstract}
Background: Crotalaria pallida Ailton is a plant belonging to the Fabaceae family, popularly known as "rattle or rattlesnake" and used in traditional medicine to treat swelling of the joints and as a vermifuge. Previous pharmacological studies have also reported anti-inflammatory, antimicrobial and antifungal activities. Nevertheless, scientific information regarding this species is scarce, and there are no reports related to its possible estrogenic and mutagenic effects. Thus, the purpose of the present study was to investigate the estrogenic potential of C. pallida leaves by means of the Recombinant Yeast Assay (RYA), seeking an alternative for estrogen replacement therapy during menopause; and to reflect on the safe use of natural products to assess the mutagenic activity of the crude extract from C. pallida leaves, the dichloromethane fraction and stigmasterol by means of the Ames test.

Methods: The recombinant yeast assay with the strain BY4741 of Saccharomyces cerevisiae, was performed with the ethanolic extract, dichloromethane fraction and stigmasterol isolated from the leaves of C. pallida. Mutagenic activity was evaluated by the Salmonella/microsome assay (Ames test), using the Salmonella typhimurium tester strains TA100, TA98, TA97 and TA102, with (+S9) and without (-S9) metabolization, by the preincubation method.

Results: All samples showed estrogenic activity, mainly stigmasterol. The ethanolic extract from C. pallida leaves showed mutagenic activity in the TA98 strain (-S9), whereas dichloromethane fraction and stigmasterol were found devoid of activity.

Conclusion: Considering the excellent estrogenic activity performed by stigmasterol in the RYA associated with the absence of mutagenic activity when evaluated by the Ames test, stigmasterol becomes a strong candidate to be used in hormone replacement therapy during menopause.
\end{abstract}

Keywords: Crotalaria pallida, Mutagenicity, Ames test, Estrogenicity, Recombinant yeast assay (RYA)

\section{Background}

Medicinal plants have been traditionally used worldwide for the treatment of various human diseases. They have proved to be abundant sources of biologically active compounds, many of which have been used as lead compounds to develop new pharmaceuticals [1].

\footnotetext{
* Correspondence: flaviabiomed@yahoo.com.br

'Department of Biological Sciences, Faculty of Pharmaceutical Sciences of Araraquara, UNESP- São Paulo State University, Rodovia Araraquara-Jaú, Km 1, 14801-902 Araraquara, São Paulo, Brazil

Full list of author information is available at the end of the article
}

Crotalaria pallida Ailton is a species that belongs to the Fabaceae family, popularly known as "rattle or rattlesnake" due to the sound of their fruits when dry [2]. This species is used in traditional medicine, having its roots used to treat swelling of the joints, and its leaves as vermifuge [3]. Pharmacological studies have demonstrated it also presents anti-inflammatory, antimicrobial and antifungal functions [4-8]. However, there are no studies verifying the estrogenic potential of C. pallida.

One of the current interests, in the pharmacological area, is to find compounds with estrogenic activity to replace estrogen in hormone replacement therapy (HRT)

\section{Ciomed Central}


during menopause, without the undesirable effects of estrogen, such as the elevation of breast cancer incidence $[9,10]$. For this reason, the development of safer and more effective drugs for menopause treatment is an urgent priority. Plants appear as a therapeutic option, since some of their constituents have the ability to bind to estrogen receptors and to act in preventing the discomfort caused by the hormonal imbalance associated with menopause. These constituents are also related to the reduction of cancer incidence, particularly estrogen-dependent cancers, such as breast cancer, cardiovascular diseases and osteoporosis [11-14].

Seeking to find options for drug development, the estrogenic potential of C. pallida leaves was investigated using the RYA (Recombinant Yeast Assay), in which recombinant yeast is utilized as an experimental model and the transcription of a reporter gene depends on the presence in the midst of compounds capable of binding to the estrogen receptor [15].

In the light of finding a good candidate for HRT and given that natural products are promising sources of novel potentially therapeutic agents, another purpose of the present study was to investigate the mutagenic activities of C. pallida by the Ames test, in order to contribute to a toxicological evaluation of the candidate samples to be employed in HRT.

\section{Methods}

\section{Chemicals}

Dimethylsulfoxide (DMSO), nicotinamide adenine dinucleotide phosphate sodium salt (NADP), D-glucose-6phosphate disodium salt, magnesium chloride, L-histidine monohydrate, D-biotin, sodium azide (SAZ), 2-anthramine (2-AA), 4-nitro-o-phenylenediamine (NOPD), mitomycin C (MMC), 2-aminofluorene (2-AF), 17- $\beta$-estradiol, Triton X-100, SDS 10\%, 2-mercaptoethanol and 4methylumbelliferyl $\beta$-D-galactoside were purchased from Sigma Chemical Co (St. Louis, USA). Oxoid Nutrient Broth No. 2 (Oxoid, England) and Difco Bacto Agar (Difco, USA) were used as bacterial media.

\section{Plant material}

Leaves of C. pallida Aiton were collected in Poços de Caldas, Minas Gerais state, Brazil, and authenticated by Prof. Dr. Luis Victor Silva Sacramento. The voucher of $C$. pallida (BOTU 28656) was deposited at the Herbarium of the Botanical Institute of São Paulo State University (UNESP), Botucatu, São Paulo.

\section{Extraction and isolation}

The leaves collected were dried in an oven with air circulation at $40^{\circ} \mathrm{C}$. The samples were weighed for three days daily until constant weight. The material was pulverized and then moistened with $70 \%$ ethanol. This material was then accommodated in percolator and submitted to leaching process with $70 \%$ ethanol. The extracts were monitored using TLC-silica gel $60-\mathrm{F}_{254}$ precoated $\mathrm{Al}$ sheets, using chloroform: methanol: $n$-propanol:water (5:6:1:4, v:v) as developing solvent, visualized using UV (254 and $366 \mathrm{~nm}$ ) and anisaldehyde sulphuric acid spray [16], until total depletion of the drug. Following, the extract was filtered with pleated filter paper and concentrated under reduced pressure $\left(40^{\circ} \mathrm{C}\right)$. After lyophilization, the $70 \%$ hydroalcoholic extract was obtained. The chromatographic determination of the $\mathrm{EtOH} \mathrm{70 \%} \mathrm{extract} \mathrm{was}$ performed by HPLC-DAD (HPLC-PDA, Jasco ${ }^{\bullet}$, Column Phenomenex Synergi Hydro ${ }^{\circ} \mathrm{RP}-18250 \times 4.6 \mathrm{~mm}$ id; $4 \mathrm{~mm}, 1.0 \mathrm{ml}$ min-1, FM: $\mathrm{A}=\mathrm{H}_{2} \mathrm{O}$ with $0.1 \%$ formic acid, $\mathrm{B}=$ acetonitrile, linear gradient $0-100 \%$ B 60 minutes). The chromatographic profile obtained from the extract of the leaves was assessed in a chromatographic comparison of the signals observed. Their absorption spectra (220-400 nm) allowed us to observe the presence of flavonoids, mainly derivatives of apigenin and luteolin (flavones) $(\lambda=254 \mathrm{~nm})$ and phenolic acids and derivatives $(\lambda=254 \mathrm{~nm})$ [17].

In order to obtain the dichloromethane fraction by partition, chromatography was performed (liquid-liquid extraction - LLE) with dichloromethane (DCM) and methanol:water $(2: 8 \mathrm{v} / \mathrm{v})(3 \mathrm{x})$, yielding two fractions with different polarities: a dichloromethane fraction (DCM-Fr) and an aqueous fraction (Aq-Fr). Each of the fractions obtained from the LLE rotary evaporator were dried in order to remove the solvent and then frozen so as to have their mass determined. The fractions obtained from the LLE were subjected to a new fractioning using two techniques: the first dichloromethane fraction (DCM-Fr) was submitted to chromatography using an open silica gel column as the stationary phase and hexane mobile phase. The second technique was applied to the Aq-Fr in Medium Pressure Liquid Chromatography (MPLC) column using packed with $\mathrm{C}_{18}$ in the reverse silica and methanol:water solvent systems. The fractions obtained in the procedure above were analyzed by HPLC-PDA in order to obtain a preliminary view of the substances. Comparing the chromatograms obtained from the MPLC fractions, the majority of the substances absorbing UV belong to the class of flavones.

Chromatography by MPLC did not result in the separation of the pure substance, making a further step of purification necessary, using a preparative HPLCPDA in order to isolate the majority of substances. The chromatographic analysis of the dichloromethane fraction allowed us to infer that the Fr 23-33 fraction was practically pure. The isolated substance was called F2. The $1 \mathrm{H}$ NMR spectrum showed characteristic signals of hydrogen steroid [18]. A comparison of the NMR chemical shifts of $1 \mathrm{H}$ NMR substance alone, with the 
records in the literature [18] allowed us to identify it as stigmasterol.

\section{Recombinant yeast assay (RYA)}

RYA was performed essentially as in Garcia-Reyero et al. [15]. Briefly, the yeast strain BY4741 (MATa ura3 $\Delta 0$ leu2 $\Delta 0$ his $3 \Delta 1$ met15 $\Delta 0$ ) (EUROSCARF, Frankfurt, Germany), which was kindly provided by Dr. Benjamin Piña (CSIC, Barcelona, Spain), was transformed together with plasmids pH5HE0 and pVitBX2 [15].

The expression plasmid pH5HE0 contained the human estrogen hormone receptor gene HEO [19], cloned into the constitutive yeast expression vector pAAH5 [20]. The reporter plasmid pVITB2x contained two copies of the pseudo-palindromic responsive estrogen element from the Xenopus laevis vitellogenin B1 gene (5'-AGTCACT GTGACC-3'), inserted into the unique KpnI site of pSFL $\Delta-178 \mathrm{~K}[21]$.

Transformed clones were first grown in $3 \mathrm{~mL}$ of rich complete medium at $30^{\circ} \mathrm{C}$. Following, they were grown overnight in a minimal medium. The final culture was adjusted to an optical density (OD) of 0.1 at $600 \mathrm{~nm}$ and distributed in the wells of a siliconized 96-well polypropylene microliter plate $\left(\mathrm{NUNC}^{\mathrm{m}}\right.$, U96 PP $0.5 \mathrm{~mL}$ ), at $90 \mu \mathrm{L}$ in the first row. Aliquots of $10 \mu \mathrm{L}$ of the crude extract, dichloromethane fraction and stigmasterol at initial concentrations of $0.01,0.03$ and $0.15 \times 10^{-6} \mathrm{~g} / \mathrm{mL}$, respectively, were dispensed into wells in the first row and serial dilutions were prepared along the plate, containing the samples with dilution factors of 1:10, 1:30, 1:90, 1:270 and 1:810. All the used concentrations are determinate in previous experiments of toxicity.

A positive control was made by adding $17-\beta$-estradiol at a final concentration of $10 \mathrm{nM}$. Moreover, we included a toxicity control by adding $10 \mathrm{nM}$ of $17-\beta$-estradiol to a sample with a dilution factor of 1:30, and 10\% DMSO as negative control.

Plates were incubated for $6 \mathrm{~h}$ at $30^{\circ} \mathrm{C}$ under $120 \mathrm{rpm}$. After incubation, $50 \mu \mathrm{L}$ of Y-PERTM (PIERCE ${ }^{\mathrm{ma}}$, Rockford, IL, USA) were added to each well and incubated at $30^{\circ} \mathrm{C}$ for further $30 \mathrm{~min}$. Afterwards, $50 \mu \mathrm{L}$ of assay buffer were added to the lysed cells. The assay buffer was prepared by mixing $100 \mathrm{~mL}$ Z-buffer, $1 \mathrm{~mL}$ Triton X-100 (Sigma), $1 \mathrm{~mL}$ SDS 10\%, $70 \mu \mathrm{L}$ 2-mercaptoethanol (Fluka) and $21 \mathrm{mg}$ of 4-methylumbelliferyl $\beta$-D-galactoside (Sigma). The Z-Buffer is a combination of: $60 \mathrm{mM} \mathrm{Na} \mathrm{HPO}_{4}$, $40 \mathrm{mM} \mathrm{NaH}{ }_{2} \mathrm{PO}_{4}, 10 \mathrm{mM} \mathrm{KCl}$ and $1 \mathrm{mM} \mathrm{MgSO}_{4}$, $\mathrm{pH}$ 7.0.

After centrifugation, plates were read in a spectrofluorometer (Synergy H1, Biotek), at $355 \mathrm{~nm}$ excitation and $460 \mathrm{~nm}$ emission wavelengths. Fluorescence was recorded for $20 \mathrm{~min}$ (one measurement per min); $\beta$-galactosidase activity was calculated as the rate of increase of fluorescence (in arbitrary units). RYA does not provide a direct measurement of the molar (or mass) concentration of endocrine disruptors, but of their estrogenic activity. For simplification, results were calculated as estradiol equivalents (EEQ), defined as the amount of estradiol that should be present to account for the observed response in a given sample. These equivalents were calculated from the lowest dilution in which the $\beta$-galactosidase activity was indistinguishable from that of the control (only vehicle).

To translate results from serial dilutions to EEQ, we assumed that hormonal dose-response curves follow a sigmoidal function,

$$
\frac{\mathrm{R}-\mathrm{R} 0}{\mathrm{Rmax}-\mathrm{R} 0}=\frac{1}{1+\frac{\mathrm{Kd}}{[\mathrm{L}]}}
$$

In which $\mathrm{R} 0, \mathrm{R}$, and $\mathrm{Rmax}$ represent $\beta$-galactosidase units obtained without ligand (or extract) addition, at a given ligand concentration [L], and at a saturating ligand concentration, respectively. Kd represents the dissociation constant of the ligand-hormone complex; its value coincides with $\mathrm{EC}_{50}$, the ligand concentration giving 50\% of the maximal response. For extract serial dilutions, plotting dilution factors versus relative response followed an inverse sigmoidal function, in which the apparent $\mathrm{EC}_{50}$ correspond to the dilution (actual or theoretical) giving $50 \%$ the response for $10 \mathrm{nM}$ estradiol. Apparent $\mathrm{EC}_{50}$ values for each sample (a minimum of two replicas with at least four points each) were calculated using standard nonlinear regression methods. These values were converted to EEQ by assuming they correspond to the $\mathrm{EC}_{50}$ of estradiol [22], $7.29 \times 10^{-9} \mathrm{~g} / \mathrm{mL}$ in our assay. Three independent experiments were done with the compounds, all of them in triplicate.

\section{Salmonella/microsome assay}

Mutagenic activity was evaluated by the Salmonella/microsome assay, using the Salmonella typhimurium tester strains TA98, TA100, TA97a and TA102, which were kindly provided by Dr. B.N. Ames (Berkeley, CA, USA), with $(+$ S9) and without (-S9) metabolization, using the preincubation method [23]. The strains were grown overnight from frozen cultures for $12-14 \mathrm{~h}$ in Oxoid Nutrient Broth No. 2. The metabolic activation mixture (S9 fraction), prepared from livers of Sprague-Dawley rats treated with the polychlorinated biphenyl mixture Aroclor 1254 $(500 \mathrm{mg} / \mathrm{kg})$, was purchased from Molecular Toxicology Inc. (Boone, NC, USA) and freshly prepared before each test. The metabolic activation system consisted of 4\% S9 fraction, $1 \% 0.4 \mathrm{M} \mathrm{MgCl} 2,1 \% 1.65 \mathrm{M} \mathrm{KCl}, 0.5 \%$ $1 \mathrm{M}$ D-glucose-6-phosphate disodium and 4\% $0.1 \mathrm{M}$ NADP, $50 \% 0.2 \mathrm{M}$ phosphate buffer and $39.5 \%$ sterile distilled water [23]. For the determination of the mutagenic activity, five different concentrations of each sample 
Table 1 Estrogenic activity expressed through the values of estradiol equivalents (EEQ) \pm standard deviation of the extracts and $\mathrm{EC}_{50}$ values of the ethanol extract of $C$. pallida, dichloromethane fraction and stigmasterol using a genetically modified strain of S. cerevisae BY4741

\begin{tabular}{ccc}
\hline Samples & EEQ $(\mathbf{n M}) \mathbf{M} \pm \mathbf{S D}$ & $\mathbf{E C}_{\mathbf{5 0}} \mathbf{( g / \mathbf { m L } )}$ \\
\hline Ethanolic extract & $14.3 \pm 4.1$ & 0.2 \\
Dichloromethane fraction & $89.0 \pm 16.0$ & 0.1 \\
Stigmasterol & $122.0 \pm 11$ & $10.5 \times 10^{-7}$ \\
17- $\beta$-estradiol & - & $7.29 \times 10^{-9}$ \\
\hline
\end{tabular}

$E E Q$, Values of estradiol equivalents (EEQ); $M \pm S D$, Mean and standard deviation; $E C_{50}$, Concentration of sample equivalent to $50 \%$ of the activity.

(0.7 to $18.9 \mathrm{mg} /$ plate for extract, 0.3 to $3.4 \mathrm{mg} / \mathrm{plate}$ for dichloromethane fraction and 0.02 to $0.5 \mathrm{mg} / \mathrm{plate}$ for stigmasterol), diluted in DMSO, were assayed. The mutagenic activity of the dichloromethane fraction and of the stigmasterol was only evaluated in the TA98 strain, because of the small amount of material available for the study and based in the fact that initially mutagenic activity was only observed for TA98. The concentrations of the samples were selected based on a preliminary toxicity test. In all subsequent assays, the upper limit of the dose range tested was either the highest non-toxic dose or the lowest toxic dose determined in this preliminary assay. Toxicity was detected either as a reduction in the number of histidine revertants (His+), or as a thinning of the auxotrophic background (i.e., background lawn).

The various concentrations of extract, fraction and isolated substance to be tested were added to $0.5 \mathrm{~mL}$ of $0.2 \mathrm{M}$ phosphate buffer or to $0.5 \mathrm{~mL}$ of $4 \% \mathrm{~S} 9$ mixture, with $0.1 \mathrm{~mL}$ of bacterial culture and then incubated at $37^{\circ} \mathrm{C}$ for $20-30 \mathrm{~min}$. Following, $2 \mathrm{~mL}$ of top agar were added and the mixture poured on to a plate containing minimal agar.

The plates were incubated at $37^{\circ} \mathrm{C}$ for $48 \mathrm{~h}$ and the His+ revertant colonies were counted manually. All experiments were analyzed in triplicate. The results were analyzed with the statistical software package Salanal 1.0 (U.S. Environmental Protection Agency, Monitoring Systems Laboratory, Las Vegas, NV, from the Research Triangle Institute, RTP, NC, USA), adopting the model of Bernstein et al. [24]. The data (revertants/plate) were assessed by means of the analysis of variance (ANOVA), followed by linear regression. The mutagenicity ratio (MR) was also calculated for each concentration tested, this being the mean number of revertants per plate with the test compound divided by the mean number of revertants per plate with the negative (solvent) control. A test solution was considered mutagenic when a dose-response relationship was detected and a two-fold increase in the number of mutants $(M R \geq 2)$ was observed in at least one concentration [1]. The standard mutagens used as positive controls in experiments without the S9 mix were NOPD $(10 \mu \mathrm{g} /$ plate) for TA98 and TA97a, SAZ (1.25 $\mu$ g/plate) for TA100 and MMC $(0.5 \mu \mathrm{g} /$ plate $)$ for TA102. In experiments with S9 activation, 2-AA (1.25 $\mu \mathrm{g} /$ plate) was used with TA98, TA97a and TA100 and 2-AF (10 $\mu \mathrm{g} /$ plate $)$ with TA102. DMSO served as negative (solvent) control.

\section{Results}

\section{Estrogenicity assay (RYA)}

The result of the estrogenic activity assessment, performed using the RYA, was given as equivalent to estradiol (EEQ) and $\mathrm{EC}_{50}$ (Table 1). The extract from C. pallida leaves obtained an EEQ of $14.3 \mathrm{nM}$ in the RYA, whereas the fraction obtained $89.0 \mathrm{nM}$. The isolated substance

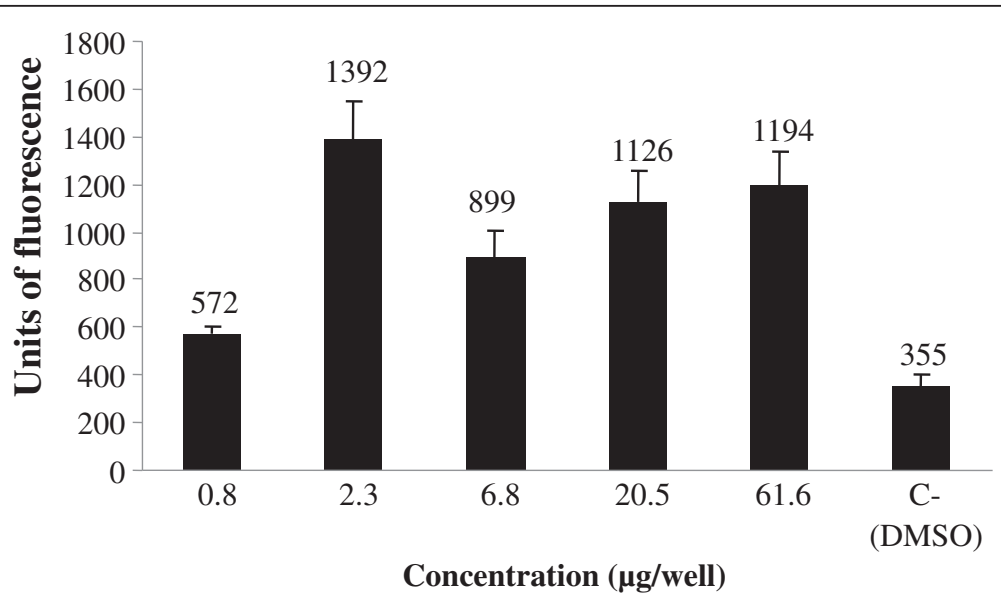

Figure 1 Estrogenic response for extract of $C$. pallida leaves in the recombinant yeast assay. Different concentrations of extract of $C$. pallida leaves ( $\mu \mathrm{g} /$ well) were added to genetically engineered, estrogen- responsive yeast cells and incubated for 6 h. The $\beta$-galactosidase activities were calculated as fluorescence units (FU). Values are averages of three independent experiments; bars indicate value ranges. Negative control, DMSO, FU = $355 \pm 21$; positive control, 17- $\beta$-estradiol, FU = $9834 \pm 985$. 


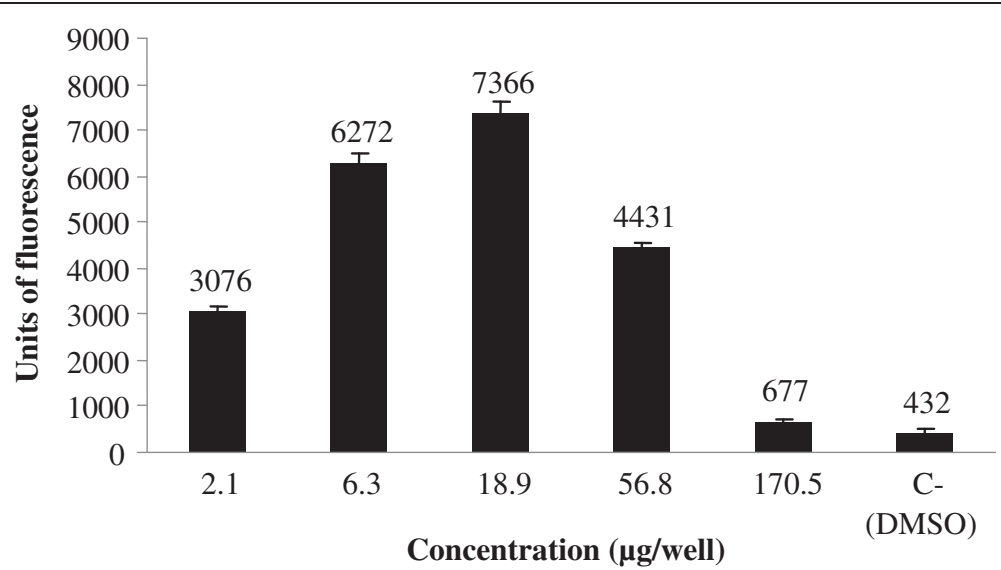

Figure 2 Estrogenic response for extract dichloromethane fraction of $C$. pallida, in the recombinant yeast assay. Different concentrations of dichloromethane fraction of C. pallida, ( $\mu \mathrm{g} /$ well) were added to genetically engineered, estrogen- responsive yeast cells and incubated for $6 \mathrm{~h}$. The $\beta$-galactosidase activities were calculated as fluorescence units (FU). Values are averages of three independent experiments; bars indicate value ranges. Negative control, DMSO, FU $=432 \pm 34$; positive control, 17- $\beta$-estradiol, $\mathrm{FU}=11490 \pm 496$.

obtained the highest value equivalent to estradiol, $122 \mathrm{nM}$. Regarding the $\mathrm{EC}_{50}$ values, stigmasterol proved to be the most potent sample, with $\mathrm{EC}_{50}$ values of $10.5 \times 10^{-7} \mathrm{~g} / \mathrm{mL}$.

Figure 1 shows the estrogenic activity, assessed by the $\beta$-galactosidase activity expressed in arbitrary units of fluorescence of five concentrations of the extract. It is possible to observe that the different concentrations tested presented significant enzymatic activation when compared to the negative control and the estrogenic activity of the extract starting from the second lowest concentration. The dichloromethane fraction (Figure 2) also generated an increase of fluorescence units, even at lower concentration that is similar to the second lowest concentration of the extract. The concentration of $18.9 \mu \mathrm{g} /$ well provided the greatest estrogenic activity for this sample. Figure 3 shows the estrogenic activity, expressed in fluorescence units, for stigmasterol isolated from C. pallida leaves. The average fluorescence was compared to negative control. This sample generated a significant activation of the $\beta$ galactosidase enzyme, at all concentrations tested, and the units of fluorescence were greater than those found in the negative control.

\section{Mutagenicity assay (Ames test)}

Table 2 shows the mean number of revertants/plate, the standard deviation (SD) and the MR after treatment with the five concentrations of crude extract, observed in $S$. typhimurium strains TA98, TA100, TA97a and TA102, in the presence $(+59)$ and absence $(-S 9)$ of metabolic activation. The mutagenic activity was considered negative for the strains TA97, TA102 and TA100 at all concentrations tested, both in the absence and in the presence of metabolism. However, in the absence of the external metabolizing system $(-S 9)$, the crude extract was mutagenic,

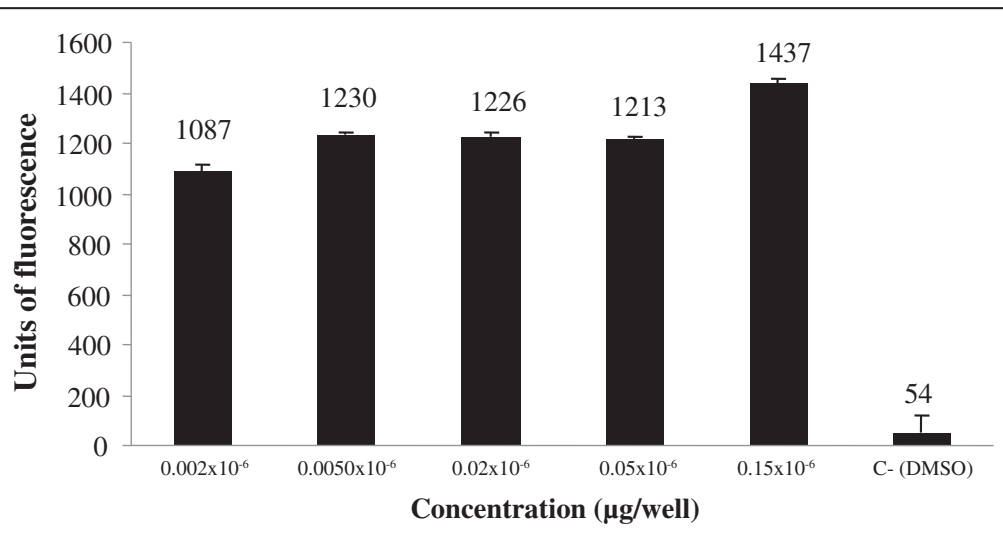

Figure 3 Estrogenic response for stigmasterol, isolated from C. pallida leaves, in the recombinant yeast assay. Different concentrations of stigmasterol, ( $\mu \mathrm{g} / \mathrm{well})$ were added to genetically engineered, estrogen- responsive yeast cells and incubated for $6 \mathrm{~h}$. The $\beta$-galactosidase activities were calculated as fluorescence units (FU). Values are averages of three independent experiments; bars indicate value ranges. Negative control, DMSO, FU = $54 \pm 16$; positive control, 17- $\beta$-estradiol, $F U=9678 \pm 167$. 
Table 2 Mutagenic activity expressed by the mean number of revertants/plate \pm standard deviation and mutagenicity ratio (in brackets) of the ethanol extract of C. pallida leaves in S. typhimurium strains in the absence (-S9) and in the presence of metabolism (+S9)

\begin{tabular}{|c|c|c|c|c|c|c|c|c|c|c|}
\hline \multicolumn{11}{|c|}{ Extract from Crotalaria pallida leaves } \\
\hline \multirow{2}{*}{$\begin{array}{l}\text { Treatment } \\
\text { mg/plate }\end{array}$} & \multicolumn{2}{|c|}{ TA97a } & \multicolumn{2}{|c|}{ TA102 } & \multirow{2}{*}{$\begin{array}{l}\text { Treatment } \\
\text { mg/plate }\end{array}$} & \multicolumn{2}{|c|}{ TA100 } & \multirow{2}{*}{$\begin{array}{l}\text { Treatment } \\
\text { mg/plate }\end{array}$} & \multicolumn{2}{|c|}{ TA98 } \\
\hline & -59 & $+\mathrm{S9}$ & $-\$ 9$ & $+\mathrm{Sg}$ & & -59 & $+\mathrm{S9}$ & & -59 & $+\mathrm{Sg}$ \\
\hline DMSO & $108 \pm 4$ & $140 \pm 21$ & $170 \pm 6$ & $196 \pm 10$ & DMSO & $110 \pm 0,6$ & $185 \pm 6$ & DMSO & $43 \pm 2$ & $20 \pm 4$ \\
\hline 0.7 & $129 \pm 14(12)$ & $177 \pm 12(1.3)$ & $150 \pm 24(0.9)$ & $224 \pm 6(1.1)$ & 0.9 & $122 \pm 2(1.1)$ & $237 \pm 13(1.3)$ & 1.8 & $51 \pm 0(1.2)$ & $18 \pm 2(0.9)$ \\
\hline 1.9 & $119 \pm 4(1.1)$ & $164 \pm 2(1.2)$ & $143 \pm 5(0.8)$ & $251 \pm 5(1.3)$ & 2.3 & $106 \pm 7(1.0)$ & $295 \pm 51(1.1)$ & 4.5 & $65 \pm 8(1.5)$ & $18 \pm 1(0.9)$ \\
\hline 3.7 & $109 \pm 5(1.0)$ & $141 \pm 5(1.0)$ & $146 \pm 6(0.9)$ & $275 \pm 19(1.4)$ & 4.5 & $145 \pm 5(1.3)$ & $203 \pm 3(1.1)$ & 9.0 & $95 \pm 13^{*}(2.2)$ & $17 \pm 2(0.9)$ \\
\hline 5.6 & $97 \pm 3(0.9)$ & $134 \pm 12(1.0)$ & $128 \pm 5(0.8)$ & $265 \pm 8(1.4)$ & 6.8 & $118 \pm 6(1.1)$ & $222 \pm 8(1.2)$ & 13.5 & $95 \pm 22^{*}(2.2)$ & $21 \pm 2(1.0)$ \\
\hline 7.4 & $117 \pm 6(1.1)$ & $174 \pm 4(1.2)$ & $194 \pm 5(1.1)$ & $219 \pm 2(1.1)$ & 9.0 & $83 \pm 5(0.8)$ & $167 \pm 36(0.9)$ & 18.0 & $77 \pm 12(1.8)$ & $19 \pm 1(0.9)$ \\
\hline Control + & $1488 \pm 18^{\mathrm{a}}$ & $2253 \pm 56^{b}$ & $1720 \pm 26^{c}$ & $1168 \pm 28^{d}$ & Control + & $1312 \pm 60^{e}$ & $1195 \pm 157^{\mathrm{b}}$ & Control + & $1050 \pm 39^{a}$ & $1063 \pm 24^{b}$ \\
\hline
\end{tabular}

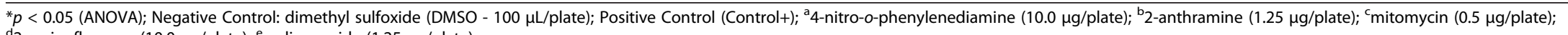
${ }^{\mathrm{d}}$ 2-aminofluorene $\left(10.0 \mu \mathrm{g} /\right.$ plate); ${ }^{\mathrm{e}}$ sodium azide $(1.25 \mu \mathrm{g} /$ plate). 
with a mutagenic ratio higher than 2.0 at the concentrations of 9.0 and $13.5 \mathrm{mg} /$ plate in the TA98 strain. Thus, the Ames test was applied to the fraction and to stigmasterol in the same conditions, using the TA98 strain, since the extract showed mutagenic activity for this strain.

As shown in Table 3, no mutagenic activity was observed for the dichloromethane fraction at any of the concentrations examined for TA98 strain. Stigmasterol was not found mutagenic for the TA98 strain in the presence and absence of metabolizing enzymes either. As shown in Table 4, no MR greater than 2 was observed.

\section{Discussion}

RYA was used to identify compounds with structurally similar estrogenic activity to the natural estrogen, 17- $\beta$ estradiol, and which can interact with the ER. This test utilizes an engineered yeast strain that harbors two foreign genetic elements: a vertebrate receptor, in this case, a human estrogen receptor (ER), and a reporter gene, whose expression is made dependent on the presence of estrogens and whose final product concentration is easy to measure [25].

The samples showed significant estrogenic activity when evaluated by RYA. The crude extract of C. pallida leaves showed an equivalent value to estradiol of $14.5 \mathrm{nM}$, which evidences that this extract has compounds with affinity for the ER present in yeast. The extract promoted a significant activation of the $\beta$-galactosidase enzyme, which could be observed due to the high fluorescence units. The same could be observed with the dichloromethane fraction, which presented an equivalent value to estradiol of $89.0 \mathrm{nM}$ and promoted a high value of fluorescence units. Since the dichloromethane fraction of leaves from this plant stood out due to their estrogenic potential, there was

Table 3 Mutagenic activity expressed by the mean number of revertants/plate \pm standard deviation and mutagenicity ratio (in brackets) of dichloromethane fraction of C. pallida in S. typhimurium strain (TA98) in the absence (-S9) and in the presence of metabolism (+S9)

\begin{tabular}{ccc}
\hline \multicolumn{3}{c}{ Dichloromethane fraction of C. pallida } \\
\hline Treatment & \multicolumn{3}{c}{ TA98 } \\
\cline { 2 - 3 } mg/plate & $-\mathbf{S 9}$ & $\mathbf{+ S 9}$ \\
\hline DMSO & $14 \pm 3$ & $27 \pm 3$ \\
0.3 & $19 \pm 2(1.4)$ & $29 \pm 6(1.1)$ \\
0.9 & $15 \pm 2(1.1)$ & $27 \pm 2(1.0)$ \\
1.7 & $15 \pm 2(1.1)$ & $29 \pm 5(1.1)$ \\
2.6 & $17 \pm 3(1.2)$ & $33 \pm 4(1.2)$ \\
3.4 & $19 \pm 4(1.4)$ & $31 \pm 2(1.1)$ \\
Control+ & $751 \pm 96^{\mathrm{a}}$ & $1088 \pm 109^{\mathrm{b}}$ \\
\hline
\end{tabular}

Negative Control: dimethyl sulfoxide (DMSO - $100 \mu \mathrm{L} /$ plate); Positive Control (Control+); ${ }^{\text {a }}$ 4-nitro-o-phenylenediamine $(10.0 \mu \mathrm{g} / \mathrm{plate})$

b 2-anthramine (1.25 $\mu \mathrm{g} /$ plate).
Table 4 Mutagenic activity expressed by the mean number of revertants/plate \pm standard deviation and mutagenicity ratio (in brackets) of stigmasterol, isolated substance of dichloromethane fraction of C. pallida leaves in S. typhimurium strain (TA98) in the absence (-S9) and in the presence of metabolism (+S9)

\begin{tabular}{ccc}
\hline & \multicolumn{2}{c}{ Stigmasterol } \\
\hline Treatment & \multicolumn{3}{c}{ TA 98 } \\
\cline { 2 - 3 } mg/plate & - S9 & +S9 \\
\hline DMSO & $16 \pm 2$ & $25 \pm 2$ \\
0.02 & $16 \pm 3(1.0)$ & $31 \pm 4(1.2)$ \\
0.04 & $17 \pm 2(1.1)$ & $23 \pm 4(0.9)$ \\
0.09 & $15 \pm 1(0.9)$ & $27 \pm 2(1.1)$ \\
0.18 & $17 \pm 0(1.1)$ & $22 \pm 1(0.9)$ \\
0.5 & $19 \pm 1(1.2)$ & $30 \pm 5(1.2)$ \\
Control + & $815 \pm 21^{\mathrm{a}}$ & $1531 \pm 36^{\mathrm{b}}$ \\
\hline
\end{tabular}

Negative Control: dimethyl sulfoxide (DMSO - $100 \mu \mathrm{L} /$ plate); Positive Control (Control+); ${ }^{\text {a }}$-nitro-o-phenylenediamine $(10.0 \mu \mathrm{g} / \mathrm{plate})$;

b2-anthramine (1.25 $\mu \mathrm{g} /$ plate).

a great interest in discovering the substance responsible for the activity that was so evident in the leaves.

The chromatographic profile of the leaves revealed the presence of flavones, for instance apigenin and luteolin derivates. Flavonoids have some structural similarities to the natural estrogen $17-\beta$-estradiol, as well as to other steroid hormones and steroid hormone antagonists [26], and can interact with the ER and induce gene expression similar to that induced by estrogens, albeit at a lower affinity [27].

Regarding the structure of flavonoids and their possible estrogenic activity, Zand et al. [26] reported that hydroxyl at the 6, 7 or 4' positions of the flavonoid provides greater estrogenic activity and more potent compounds with 2-4 hydroxyl groups, namely, at least one in the 7 position of the ring $\mathrm{A}$ and another in the 4' position of ring $\mathrm{B}$. The presence of these hydroxyl groups is essential for the estrogenic activity because they mimic the hydroxyl at the 3 and 17 position, found in the $17-\beta$-estradiol molecule [28]. Furthermore, the presence of a double bond between carbons 2 and 3 of the ring $C$ is essential for the estrogenic activity [26]. These structural features are exhibited by the apigenin and luteolin molecules, which allow a good interaction with ER.

However, derivatives of flavonoids, such as apigenin and luteolin, usually appear glycosylated [29], and this glycosylation can eliminate the free hydroxyl that is essential for the interaction with ERs or substituents may provide steric hindrance that also hinders the interaction with ERs. Furthermore, the ortho positioning between two hydroxyl groups may serve to reduce estrogenicity, due to the avoidance of direct interaction with ER [30], as observed with the luteolin molecule. Thus, these flavones were probably 
not responsible for the estrogenic activity performed by the extract.

In view of the promising results obtained in experiments with extract of leaves and considering that the extract is a complex mixture of several unknown organic compounds [1], the evaluation of isolated compounds is even more relevant. In this context, stigmasterol was isolated from the dichloromethane fraction of leaves and, following, its estrogenic activity assessed by RYA.

The results for stigmasterol in RYA showed that it is highly likely that this substance is responsible for the high estrogenicity found in leaves of C. pallida, since it was able to provide the highest result equivalent to estradiol $(122.0 \mathrm{nM})$ and an important $\mathrm{EC}_{50}$ value of $10.5 \times 10^{-7} \mathrm{~g} / \mathrm{mL}$.

Stigmasterol belongs to the class phytosteroids extracted from species of plants. Among the most common phytosteroids are $\beta$-sisterol, campesterol and stigmasterol. Chemically, they are alcohols consisting of 28 or 29 carbon atoms, similar to cholesterol [31].

The advantages of phytosteroids result from its biodegradability, the ability to affect numerous biological processes through membranes, to bind to specific hormone receptors and to be modified by synthetic methods [32-34].

The structural similarity between the molecule and stigmasterol from 17- $\beta$-estradiol (Figure 4) is remarkable, justifying the high estrogenic activity found in this sample by means of the RYA.

Since one of the purposes of this study was to search for compounds with estrogenic activity that could be used in hormone replacement therapy, the results obtained for the samples, mainly for stigmasterol, in the RYA, make these substances possible candidates.

Regarding the safe use of natural products, the mutagenic activity of the crude extract of C. pallida leaves, dichloromethane fraction and stigmasterol were assessed by the Ames test. Although the crude extract of C. pallida leaves showed good results when assessed as for its estrogenic activity, it proved to be mutagenic when evaluated by the Ames test. The extract was mutagenic for the TA98 strain, in the absence of metabolic activity. This allows us to state that this extract has direct mutagens acting as per the mechanism of frameshift.

In relation to the study of the mutagenic potential of flavonoids, Rietjens et al. [35] have described essential features in the flavonoid structure for the mutagenic activity to be present, such as: a free hydroxyl at the 3 position of the ring $C$, double bond between the 2 and 3 positions and the keto group at the 4 position. These characteristics are fundamental for the presence of mutagenic activity because they allow the hydroxyl at the 3 position to tautomerize molecule for molecule 3-keto. However, the apigenin and luteolin molecules do not have hydroxyl at the 3 position of the ring $C$, which may suggest that these substances are not responsible for the mutagenic activity found in the extract.

The literature reports that pyrrolizidine alkaloids are often found in Crotalaria species, including C. pallida [36,37]. Previous studies have demonstrated that alkaloids are able to induce chromosomal aberrations in the $\mathrm{CHO}$ (Chinese Hamster Ovary) [38] cell line, mutagenicity in Chinese hamster lung cells (CHL) [39], sister chromatid exchange in human peripheral lymphocytes [40] and increase the frequency of micronuclei and sister chromatid exchange in meristematic cells of Allium cepa [41]. The hepatotoxic activity of pyrrolizidine alkaloids probably results from the high reactivity of alkylating pyrrole derivatives, generated during enzymatic metabolism [42]. Both alkaloid molecules and metabolites are reactive alkylating agents capable of forming covalent bonds with stable macromolecules $[43,44]$. Due to the ability of pyrrolizidine alkaloids to interact with the genetic material, their involvement has been evidenced with mutagenicity and carcinogenesis [43].

In this study, the dichloromethane fraction and stigmasterol did not show mutagenic activity when evaluated by the Ames test in the TA98 strain. Considering the promising estrogenic activity of this isolated substance, a lack of mutagenic effect in bacterial systems is highly relevant.

Phytosterols such as stigmasterol are known as antioxidants [45], playing a role in the chemoprevention of DNA

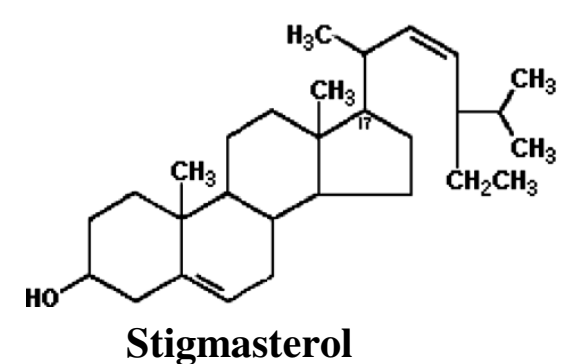

Stigmasterol<smiles>CC12CCC3c4ccc(O)cc4CCC3C1CCC2O</smiles>

17- $\beta$-estradiol

Figure 4 Structural similarity between stigmasterol and 17- $\beta$-estradiol. 
damage induced by oxidative radicals [46]. The exact mechanism by which phytosteroids offer protection against cancer is not understood, but there are theories proposing their effect on the structure of cell membranes, on the fluidity of cell membranes, on enzymes bound to membranes, on signal transduction pathways, on apoptosis, on membrane integrity, on the immune function, on the estrogenic properties on the tissue and on acids and neutral steroids in the colon [31].

Lim et al. [47] reported stigmasterol as a substance with high antimutagenic activity in Gleditsia sinensis Lam, Leguminosae, obtaining a reduction of $51.2 \%$ and $64.2 \%$ of mutagenicity against MNNG (N-methyl-N'-nitronitrosoguanidine) and 4-NQO (4-nitroquinoline-N-oxide) mutagens, respectively, by means of in vitro assay, referring to the application of stigmasterol as an anticancer agent, but emphasizing the need for in vivo studies. Substances with antimutagenic potential increase the efficiency of the repair mechanisms of mutations caused by mutagens or cause the inactivation of the mutagenic substance. As a result, these substances act as protective agents, reducing the frequency of DNA damage. In both cases, however, they act before the disordered multiplication of cells or tumor formation [48].

Considering the promising estrogenic activity and that stigmasterol might be successfully incorporated into pharmaceutical products, the absence of a mutagenic effect in the Ames assay is a positive step towards determining its safe use in hormone replacement therapy during menopause.

\section{Conclusions}

In conclusion, this study evidenced that the crude extract of C. pallida leaves has an estrogenic effect. Nevertheless, the present results indicate that this extract should be used with caution because it might be mutagenic. Considering that medicinal herbs contain complex mixtures of thousands of components that can act alone or synergistically, the estrogenic activity of dichloromethane fraction and stigmasterol isolated from $C$. pallida leaves with absence of a mutagenic effect in the Ames assay is highly relevant, since these samples may be successfully incorporated into pharmaceutical products with an important role in hormone replacement therapy.

\author{
Abbreviations \\ NOPD: 4- Nitro-o-phenylenediamine; SAZ: Sodium azide; \\ MMC: Mitomycin C; 2-AA: 2-Anthramine; 2-AF: 2-Aminofluorene; \\ DMSO: Dimethylsulfoxide; PBS: Phosphate buffer saline; +S9: \\ With metabolization; -S9: Without metabolization; \\ MR: Mutagenicity ratio.
}

\section{Competing interests}

The authors declare that they have no competing interests.

\section{Authors' contributions}

PKB designed and performed the experiments, interpreted the results and drafted the manuscript. APSO, MSC and FAR designed and performed the Recombinant Yeast Assay. LGE and CHN participated in the experiments of the Ames test. MSFM and WV prepared the ethanol extract of C. pallida and dichloromethane fraction, and isolated the stigmasterol. FAR and EAV critically read the manuscript and participated in its revision. All authors have read and approved the final manuscript.

\section{Acknowledgements}

The development of this study was supported by São Paulo Research Foundation (FAPESP) and the Brazilian Federal Agency for Support and Evaluation of Graduate Education (CAPES).

\section{Author details}

${ }^{1}$ Department of Biological Sciences, Faculty of Pharmaceutical Sciences of Araraquara, UNESP- São Paulo State University, Rodovia Araraquara-Jaú, Km 1, 14801-902 Araraquara, São Paulo, Brazil. ${ }^{2}$ Chemical Institute of Araraquara, UNESP-São Paulo State University, c.p. 355, 14800-900 Araraquara, São Paulo, Brazil.

Received: 20 March 2013 Accepted: 2 September 2013

Published: 4 September 2013

\section{References}

1. Resende FA, Munari CC, Bentos MNA, Tavares DC, Bastos JK, da Silva Filho $A A$, Varanda EA: Comparative studies of the (anti) mutagenicity of Baccharis dracunculifolia and artepillin c by the bacterial reverse mutation test. Molecules 2012, 7(3):2335-2350.

2. Everist SL: Poisonous plants of Australia. Australia: Angus and Robertson Publishers; 1974:284-295.

3. Jain SK, Borthakur SK: Etnobotany of the Mikers of India. Econ Bot 1980, 34(3):264-272.

4. Ko H, Weng J, Tsao L, Yen M, Wang J, Lin CA: Anti-inflammatory flavonoids and pterocarpanoid from Crotalaria pallida and C. assamica. Bioorg Med Chem Lett 2004, 14:1011-1014.

5. Pelegrini PB, Farias LR, Saude ACM, Costa FC, Bloch C, Silva LP, Oliveira AS, Gomes EM, Sales MP, Franco OL: A novel antimicrobial peptide from Crotalaria pallida seeds with activity against human and phytopathogens. Curr Microbio/ 2009, 59:400-404.

6. Weng JR, Tsao LT, Yen MH, Wang JP, Lin CN: Anti-inflammatory constituents and new pterocarpanoid of Crotalaria pallida. J Nat Prod 2003, 66:404-407.

7. Arzt J, Mount ME: Hepatotoxicity associated with pyrrolizidine alkaloid (Crotalaria spp) ingestion in a horse on Easter Island. Vet Hum Toxicol 1999, 41:96-99.

8. Lin MW, Tsao LT, Huang LJ, Kuo SC, Weng JR, Ko HH, Lin CN, Lee MR, Wang JP: Inhibition of lipopolysaccharide-stimulated NO production by crotafuran B in RAW 264.7 macrophages involves the blockade of NFkappaB activation through the increase in IkappaBalpha synthesis. Toxicol Appl Pharmacol 2006, 210:108-115.

9. Santen RJ, Allred DC, Ardoin SP, Archer DF, Boyd N, Braunstein GD, Burger HG, Colditz GA, Davis SR, Gambacciani M, Gower BS, Henderson WW, Karas RH, Kleerekoper M, Lobo RA, Manson JE, Marsden J, Martin KA, Martin L, Pinkerton JV, Rubinow DR, Thiboutot DM, Utian WH: Postmenopausal hormone therapy: an Endocrine Society scientific statement. J Clin Endocrinol Metab 2010, 95:1-66.

10. Sturdee DW, Pines A: International Menopause Society Writing Group. Updated IMS recommendations on postmenopausal hormone therapy and preventive strategies for midlife health. Climacteric 2011, 14:302-320.

11. Boberg J, Mandrup KR, Jacobsen PR, Isling LK, Hadrup N, Berthelsen L, Elleby A, Kiersgaard M, Vinggaard AM, Hass U, Nellemann C: Endocrine disrupting effects in rats perinatally exposed to a dietary relevant mixture of phytoestrogens. Reprod Toxicol 2013, 40C:41-51.

12. Castelo-Branco C, Soveral I: Phytoestrogens and bone health at different reproductive stages. Gynecol Endocrinol 2013, 29:735-743.

13. Gaete L, Tchernitchin AN, Bustamante R, Villena J, Lemus I, Gidekel M, Cabrera G, Astorga P: Daidzein-estrogen interaction in the rat uterus and its effect on human breast cancer cell growth. J Med Food 2012, 15:1081-1090 
14. Klein $C B$, King $A A$ : Genistein genotoxicity: critical considerations of in vitro exposure dose. Toxicol Appl Pharmacol 2007, 224:1-11.

15. Garcia-Reyero N, Grau E, Castillo M, López de Alda MJ, Barceló D, Piña B: Monitoring of endocrine disruptors in surface waters by the yeast recombinant assay. Environ Toxicol Chem 2001, 20:1152-1158.

16. Wagner $\mathrm{H}$, Bladt S, Zgainski EM: Plant drug analysis: a thin layer chromatography atlas. Berlin: Springer; 2003.

17. Gordon MC, David JN: Natural product drug discovery in the next millennium. Pharm Biol 2001, 39:8-17.

18. Kamboj A, Saluja AK: Isolation of stigmasterol and $\beta$-sitosterol from petroleum ether extract of aerial parts of Ageratum conyzoides (Asteraceae). Int J Pharm Sci 2011, 3:94-96.

19. Green $S, C$ hambon $P$ : The oestrogen receptor: from perception to mechanism. In Nuclear hormone receptors. Edited by PARKER MG. London: Academic; 1991:15-38

20. Schneider JC, Guarente L: Vectors for expression of cloned genes in yeast: regulation, overproduction, and underproduction. Methods Enzymo/ 1991, 194:373-388.

21. Garcia-Reyero N, Requena V, Petrovic M, Fischer B, Hansen PD, Díaz A, Ventura F, Barceló D, Piña B: Estrogenic potential of halogenated derivatives of nonylphenol ethoxylates and carboxylates. Environ Toxicol Chem 2004, 23:705-711.

22. Brix R, Noguerol TN, Piña B, Balaam J, Nilsen AJ, Tollefsen KE, Levy W, Schramm KW, Barceló D: Evaluation of the suitability of recombinant yeast-based estrogenicity assays as a pre-screening tool in environmental samples. Environ Int 2010, 36:361-367.

23. Maron DM, Ames BN: Revised methods for the Salmonella mutagenicity test. Mutat Res 1983, 113:173-215.

24. Bernstein L, Kaldor J, Mccann J, Pike MC: An empirical approach to the statistical analysis of mutagenesis data from the Salmonella test. Mutat Res 1982, 97:267-281.

25. Garcia-Reyero N, Piña B, Grimalt JO, Fernández P, Fonts R, Polvillo O, Martrat B: Estrogenic activity in sediments from European mountain lakes. Environ Sci Technol 2005, 15(39):1427-1435.

26. Zand RS, Jenkins DJ, Diamandis EP: Steroid hormone activity of flavonoids and related compounds. Breast Cancer Res Treat 2000, 62:35-49.

27. Ferguson LR: Role of plant polyphenols in genomic stability. Mutat Res 2001, 475:89-111.

28. Le Bail JC, Varnat F, Nicolas JC, Habrioux G: Estrogenic and antiproliferative activities on MCF-7 human breast cancer cells by flavonoids. Cancer Lett 1998, 130:209-216.

29. Ward HA, Kuhnle GG: Phytoestrogen consumption and association with breast, prostate and colorectal cancer in EPIC Norfolk. Arch Biochem Biophys 2010, 501(1):170-175.

30. Choi SY, Ha TY, Ahn JY, Kim SR, Kang KS, Hwang IK, Kim S: Estrogenic activities of isoflavones and flavones end their structure-activity relationships. Planta Med 2008, 74:25-32.

31. Awad AB, Fink CS: Phytosterols as anticancer dietary components: evidence and mechanism of action. J Nut 2000, 130:2127-2130.

32. Svobodov H, Nonappa Wimmer Z, Kolehmainen E: Design, synthesis and stimuli responsive gelation of novel stigmasterol-amino acid conjugates. J Colloid Interface Sci 2011, 361:587-593.

33. Šustekov J, Drasar P, Šaman D, Wimmer Z: Stigmasterol-based novel low molecular weight/mass organic gelators. Molecules 2011, 16:9357-9367.

34. Jurcek O, Ikonen S, Buricov L, Wimmerov M, Wimmer Z, Drasar P: Succinobucol's new coat - conjugation with steroids to alter drug effect and bioavailability. Molecules 2011, 6:9404-9420

35. Rietjens IMCM, Boersma MG, Van der Woude H, Jeurissen SMF, Schutte ME, Alink GM: Flavonoids and alkenylbenzenes: mechanisms of mutagenic action and carcinogenic risk. Mutat Res 2005, 574:124-138.

36. Fletcher MT, Mckenzie RA, Blaney BJ, Reichmann KG: Pyrrolizidine alkaloids in Crotalaria taxa from northern Australia: risk to grazing livestock. J Agric Food Chem 2009, 57:311-319.

37. Flores AS, Tozzi AMGA, Trigo JR: Pyrrolizidine alkaloid profiles in Crotalaria species from Brazil: chemotaxonomic significance. Biochem Syst Ecol 2009, 37:459-469.

38. Sasaki YF, Yamada H, Shimoi K, Kinae N, Tomita I, Matsumura H, Ohta T, Sjirasu $Y$ : Enhancing effects of heterocyclic amines and -carbolines on the induction of chromosome aberrations in culture mammalian cells. Mutat Res 1992, 269:79-95.
39. Nakayasy M, Nakasato F, Sakamoto H, Terada M, Sugimura T: Mutagenic activity of norharman and Harman in Chinese lung cells in assay with diphtheria toxin resistance as a marker. Cancer Lett 1983, 17:249-255.

40. Madle E, Obe G, Hansen J, Ristow H: Harman and norharmane: induction of sister-chromatid exchanges in human peripheral lymphocytes in vitro and interaction with isolated DNA. Mutat Res 1981, 90:433-442.

41. Hazen MJ, Gutiérrez-Gonzáles MG: UV-mediated toxic bioactivity of harmine in the meristematic cells of Allium cepa. Mutagenesis 1988, 3:333-337.

42. Petzinger E: Pyrrolizidine alkaloids and seneciosis in farm animals. Part 1: Occurrence, chemistry and toxicology. Tierarztl Prax Ausg G Grosstiere Nutztiere 2011, 4:221-230.

43. Loureiro APM, Di Massio P, Medeiros MHG: Formação de adutos exocíclicos com bases de DNA: implicações em mutagênese e carcinogênese. Quim Nova 2002, 25(5):777-793.

44. Griffin DS, Segal HJ: Genotoxicity and cytotoxicity of selected pyrrolizidine alkaloids, a possible alkenal metabolite of the alkaloids and related alkenals. Toxicol Appl Pharmacol 1986, 86:227-234.

45. De Jing A, Plat J, Mensink R: Metabolic effects of plantsterols and stanols. J Nut Biochem 2003, 14:362-369.

46. Hui-Lian W, Qian-Rong L, Jian Y, Zhao-Feng L, Yu-Zhen W: The protective effect and mechanism of soybean oil and its extracts in DNA damage in human ECV304 cells exposed to UV-C. Biochim Biophys Acta 2003, 1626(1-3):19-24.

47. Lim JC, Park JH, Budesinsky M, Kasal A, Han YH, Koo BS, Lee SI, Lee DU: Antimutagenic constituents from the thorns of Gleditsia sinensis. Chem Pharm Bull 2005, 53(5):561-564.

48. Rezende JR, Rodrigues SB, Jabor IAS, Pamphile JA, Rocha CLMSC: Efeito antimutagênico do látex de Euphorbia tirucalli no sistema metionina em Aspergillus nidulans. Biol Sci 2004, 26(4):481-484.

doi:10.1186/1472-6882-13-216

Cite this article as: Boldrin et al:: Estrogenic and mutagenic activities of Crotalaria pallida measured by recombinant yeast assay and Ames test. BMC Complementary and Alternative Medicine 2013 13:216.

\section{Submit your next manuscript to BioMed Central and take full advantage of:}

- Convenient online submission

- Thorough peer review

- No space constraints or color figure charges

- Immediate publication on acceptance

- Inclusion in PubMed, CAS, Scopus and Google Scholar

- Research which is freely available for redistribution

Submit your manuscript at www.biomedcentral.com/submit
C) Biomed Central 